\title{
Dung Beetles (Coleoptera: Scarabaeidae) Attracted to Dung of the Largest Herbivorous Rodent on Earth: a Comparison With Human Feces
}

\author{
ANDERSON PUKER,${ }^{1,2}$ CÉSAR M. A. CORREA,${ }^{3}$ VANESCA KORASAKI ${ }^{4}$ KLEYTON R. FERREIRA, ${ }^{3}$ \\ AND NAIARA G. OLIVEIRA ${ }^{5}$
}

Environ. Entomol. 42(6): 1218-1225 (2013); DOI: http://dx.doi.org/10.1603/EN13100

\begin{abstract}
The capybara, Hydrochoerus hydrochaeris (L.) (Rodentia: Caviidae), is the largest herbivorous rodent on Earth and abundant in the Neotropical region, which can provide a stable food source of dung for dung beetle communities (Coleoptera: Scarabaeidae: Scarabaeinae). However, the use of capybara dung by dung beetles is poorly known. Here, we present data on the structure of the dung beetle community attracted to capybara dung and compare with the community attracted to human feces. Dung beetles were captured with pitfall traps baited with fresh capybara dung and human feces in pastures with exotic grass (Brachiaria spp.), patches of Brazilian savanna (Cerrado), and points of degraded riparian vegetation along the Aquidauana river in Anastácio and Aquidauana, Mato Grosso do Sul, Brazil. In traps baited with human feces, 13,809 individuals of 31 species were captured, and in those baited with capybara dung 1,027 individuals belonging to 26 species were captured. The average number of individuals and species captured by the traps baited with human feces was greater than for capybara dung in all habitats studied. Composition of the communities attracted to human feces and capybara dung formed distinct groups in all habitats. Despite the smaller number of species and individuals captured in capybara dung when compared with human feces, capybara dung was attractive to dung beetles. In Brazil, the legalization of hunting these rodents has been debated, which would potentially affect the community and consequently the ecological functions performed by dung beetles that use the feces of these animals as a resource. In addition, the knowledge of the communities associated with capybaras may be important in predicting the consequences of future management of their populations.
\end{abstract}

KEY WORDS biodiversity conservation, capybara dung, coprophagous beetle, feeding preference, Scarabaeoidea

Dung beetles (Coleoptera: Scarabaeidae: Scarabaeinae) comprise $\approx 6,000$ species found worldwide, with 1,250 species described for the Neotropical region (Hanski and Cambefort 1991), of which 600 have been reported in Brazil (Vaz-de-Mello 2000). The feeding behavior of dung beetles is quite varied, including carcasses, fungi, fruits, and decaying plant material, but coprophagy is most frequent (e.g., Halffter and Matthews 1966). Dung beetles also have different resource allocation strategies, including dweller species that live within a dung pat and do not exhibit resource allocation; roller species that remove portions of dung,

\footnotetext{
${ }^{1}$ Programa de Pós-Graduação em Entomologia, Departamento de Entomologia, Universidade Federal de Viçosa, 36570-000 Viçosa-MG, Brazil.

${ }^{2}$ Corresponding author, e-mail: pukeragro@gmail.com.

${ }_{3}^{3}$ Programa de Pós-Graduação em Agronomia, Laboratório de Entomologia, Universidade Estadual de Mato Grosso do Sul, Rodovia Aquidauana/CERA km 12, 79200-000 Aquidauana-MS, Brazil.

${ }^{4}$ Departamento de Biologia, Setor de Ecologia, Universidade Federal de Lavras, 37200-000 Lavras-MG, Brazil.

${ }^{5}$ Universidade Estadual de Mato Grosso do Sul, Rodovia Aquidauana/CERA km 12, 79200-000 Aquidauana-MS, Brazil.
}

which are rolled various distances and then buried; and tunneler species that construct tunnels below or adjacent to the food resource and transport dung into the bottom (Halffter and Matthews 1966). This diversity of feeding habits affects characteristics of behavior, morphology, and development (Halffter and Matthews 1966, Hanski and Cambefort 1991), and this may be a determining factor in species richness in the Neotropical region (Halffter and Favila 1993).

The availability of mammal dung to the dung beetles varies in time and space, and is important for the stabilization of communities (Hernández and Vaz-deMello 2009). The attractiveness of this resource may also vary depending on the feeding habits of these animals (carnivore, herbivore, and omnivore), but some studies show that dung beetles are more attracted to feces of omnivorous mammals (e.g., Fincher et al. 1970, Martín-Piera and Lobo 1996, Filgueiras et al. 2009, Whipple and Hoback 2012). In Brazil, dung beetles have been sampled using traps baited with different types of baits, including the feces of domestic (e.g., Flechtmann et al. 2009, Louzada and Carvalho e 
Silva 2009, Correa et al. 2013) and wild animals (e.g., Filgueiras et al. 2009, Flechtmann et al. 2009).

The capybara, Hydrochoerus hydrochaeris (L.) (Rodentia: Caviidae) is the largest herbivorous rodent on Earth, measuring from 1.0 to $1.3 \mathrm{~m}$ in length and the weight of adults ranges from 35 to $65 \mathrm{~kg}$ (Woods and Kilpatrick 2005). It is a semiaquatic rodent that inhabits the margins of water bodies in groups that can reach $>20$ individuals (Woods and Kilpatrick 2005). Capybaras feed exclusively on plants and are distributed from Panama to northern Argentina (Woods and Kilpatrick 2005). Several dung beetle species have been found in the nests of rodents (e.g., Howden et al. 1956, Howden and Cartwright 1963, Halffter and Mathews 1966, Anduaga and Halffter 1991, Anduaga 2007), but no studies have been conducted to assess the community structure of dung beetles attracted to the feces of the largest herbivorous rodent on the planet.

Here, we used a wide sampling effort to capture dung beetles in pastures with exotic grass (Brachiaria spp.), patches of the Brazilian savanna (Cerrado), and points of degraded riparian forest along the Aquidauana river (in Anastácio and Aquidauana, Mato Grosso do Sul, Brazil) using pitfall traps baited with fresh capybara dung (native herbivores) and human feces (exotic omnivores) to test the following hypotheses: 1) capybara dung attracts lower abundance and richness than human feces in the three systems; and 2) there are differences in community structure and species composition attracted to the two feces types in the three systems. Our null hypothesis is that the number of species, abundance, and species composition attracted to the two feces types is similar in the three systems. Because humans are omnivores and dung beetles often prefer omnivore dung, we believe that the capture will be greater in human feces than in the capybara dung. In addition, human feces is among the most attractive types of dung to most of the dung beetle species (Howden and Nealis 1975), and is available at any study site in the world (Larsen and Forsyth 2005) being used in most articles with dung beetles (e.g., Larsen 2012, Korasaki et al. 2013).

\section{Materials and Methods}

Study Sites and Sampling Procedures. The study was developed in a transitional region of the Cerrado and Pantanal ecosystems, in Anastácio (20 45' $45^{\prime \prime} \mathrm{S}$, $\left.55^{\circ} 43^{\prime} 49^{\prime \prime} \mathrm{W}\right)$ and Aquidauana $\left(20^{\circ} 27^{\prime} 28^{\prime \prime} \mathrm{S}, 55^{\circ} 50^{\prime} 16^{\prime \prime}\right.$ W), Mato Grosso do Sul, Brazil, with annual rainfall ranging from 1,200-1,300 $\mathrm{mm}$ and mean annual temperature of $26^{\circ} \mathrm{C}$. Dung beetles were sampled in 30 areas that were separated by at least $300 \mathrm{~m}$. We selected 10 areas of pastures with exotic grass ( $\mathrm{Bra}$ chiaria spp.), 10 of native forest fragments (Brazilian savanna), and 10 points of degraded riparian vegetation along the Aquidauana river, five areas on the right bank and five on the left bank of the river. On the river margins, the capybara are extremely plentiful.

Sampling was carried out during the middle of the rainy season in December 2011 to January 2012. In Brazil this is the period of greatest activity and rich- ness of dung beetles (e.g., Almeida et al. 2011, Abot et al. 2012). In each area, we installed two parallel linear transects spaced by $20 \mathrm{~m}$ from each other. One transect received a set of five pitfall traps baited with fresh capybara dung $(\approx 40 \mathrm{~g})$ and the other transect received five traps baited with human feces $(\approx 40 \mathrm{~g})$, totaling a sampling effort of 300 traps. The distance between traps within each transect was $100 \mathrm{~m}$ to ensure independence of the samples (Larsen and Forsyth 2005).

Dung beetles were sampled during $48 \mathrm{~h}$ using pitfall traps $(20 \mathrm{~cm}$ in diameter and $15 \mathrm{~cm}$ in height) installed at ground level and covered with a plastic lid to reduce drying of the bait and prevent damage from rainfall. Inside each trap, $250 \mathrm{ml}$ of a saline + neutral detergent solution (1.5\%) was added, and the baits were placed in plastic containers $(50 \mathrm{ml})$ at the center of each trap using a wire. Fresh capybara dung was collected every morning along the banks of the João Dias creek in the city of Aquidauana where these animals are commonly found.

The beetles captured were sent to the Federal University of Mato Grosso (UFMT; Cuiabá, Mato Grosso, Brazil) where they were identified by Dr. Fernando Z. Vaz-de-Mello. Vouchers are deposited in the State University of Mato Grosso do Sul (UEMS; Aquidauana, Mato Grosso do Sul, Brazil) and also in the Entomology Section of the Zoological Collection of the UFMT.

Data Analysis. We performed analyses for each of the three systems separately. We performed a series of Generalized Linear Models (GLMs) to determine whether the baits differed with respect to the average number of individuals and species of dung beetles sampled per transect in the three systems. We used the baits as the explanatory variables and richness and abundance as response variables. All GLMs were submitted to residual analysis, so as to evaluate adequacy of error distribution (Crawley 2002). All analyses were performed using the free software R (R Development Core Team 2013).

Comparisons between the number of accumulated species per baits in each system were performed visually with the curve of the $95 \%$ CI. In an additional attempt to evaluate the efficiency of our sampling program, we assessed the completeness of each system by calculating the number of observed species (Sobs) as a percentage of the total species richness, which was estimated based on the average of three abundancebased nonparametric estimators: ACE, Chao 1, and Jackknife 1, using the formula: Sampling Efficiency = $[$ Sobs $\times 100 /((\mathrm{ACE}+\mathrm{Chaol}+\mathrm{Jack} 1) / 3)]$. The richness estimates were calculated with the software EstimateS 7.5, with 500 randomizations (Colwell 2005).

We used a nonmetric multidimensional scaling (NMDS) analysis to examine differences in composition of dung beetle communities between baits in each system. This was done using root-square transformed and standardized abundance data, using a Bray-Curtis index to measure similarity between points. We performed an analysis of similarity (ANOSIM) (Clarke and Warwick 2001) to verify statistical differences between groups formed by the NMDS. These analyses 
Table 1. Estimated richness of dung beetles (Coleoptera: Scarabaeinae) sampled with capybara dung and human feces in Brazilian savanna, riverbank, and pasture with exotic grass

\begin{tabular}{|c|c|c|c|c|c|c|}
\hline \multirow[t]{2}{*}{ Estimators } & \multicolumn{2}{|c|}{$\begin{array}{c}\text { Brazilian } \\
\text { savanna }\end{array}$} & \multicolumn{2}{|c|}{ Riverbank } & \multicolumn{2}{|c|}{ Pasture } \\
\hline & $\mathrm{CD}$ & $\mathrm{HF}$ & CD & $\mathrm{HF}$ & $\mathrm{CD}$ & $\mathrm{HF}$ \\
\hline Observed richness & 23 & 27.00 & 18 & 25 & 11 & 23 \\
\hline $\mathrm{ACE}$ & 33.23 & 34.01 & 20.37 & 32.48 & 14.11 & 27.64 \\
\hline Chao 1 & 28 & 32.00 & 19.5 & 27.50 & 12.50 & 33.00 \\
\hline Jackniffe 1 & 28.88 & 32.88 & 22.9 & 30.88 & 13.94 & 27.90 \\
\hline Sampling efficiency (\%) & 76.57 & 81.91 & 86.03 & 82.54 & 81.38 & 77.93 \\
\hline
\end{tabular}

CD, capybara dung; HF, human feces.

were performed using the Primer v. 6 software (Clarke and Gorley 2006). We used the Similarity PercentageSIMPER (Clarke 1993) to determine the contribution that individual species had on distinguishing differences in community structure among the baits. This analysis was performed using Past (Hammer et al. 2001). To compare foraging strategies (functional guilds) between baits, we classified the sampled species as dwellers, rollers, or tunnelers, as proposed by Halffter and Matthews (1966).

\section{Results}

Abundance and Richness. We collected 14,836 individuals from 34 dung beetle species during the study, distributed across 6 tribes and 17 genera: Ateuchini $(7$ species, 4 genera), Coprini (11 species, 3 genera), Oniticellini ( 2 species, 1 genera), Deltochilini (8 species, 4 genera), Onthophagini (2 species, 2 genera), and Phanaeini (4 species, 3 genera). Human feces presented the highest number of species and individuals, with a total of 31 species and 13,809 individuals, while the capybara dung presented 26 species and 1,027 individuals.

Sampling efficiency was high for both baits used, ranging from 77.93 to $82.54 \%$ for human feces and $76.57-86.03 \%$ for capybara dung (Table 1). The species accumulation curves showed no difference in overall accumulated richness between the two baits for all systems (Fig. 1). The traps baited with human feces captured more average number of individuals than the patches of Brazilian savanna $\left(\mathrm{F}_{1,18}=27.85\right.$; $P<0.0001)$, riverbanks $\left(\mathrm{F}_{1,18}=50.25 ; P<0.0001\right)$, and pastures with exotic grass $\left(\mathrm{F}_{1,18}=26.89 ; P<0.0001\right)$ compared with traps baited with capybara dung (Fig. 2 ). The average number of species captured by the traps baited with human feces was also higher in the patches of Brazilian savanna $\left(\mathrm{F}_{1,18}=19.33 ; P<\right.$ $0.0001)$, riverbanks $\left(\mathrm{Chi}_{1,18}=21.55 ; P<0.0001\right)$, and pastures with exotic grass $\left(\mathrm{F}_{1,18}=51.47 ; P<0.0001\right)$ when compared with capybara dung (Fig. 2).

Community Structure and Species Composition. Dung beetles community structure and species composition were different when comparing the capybara dung and human feces baits $(\mathrm{R}=0.35 ; P<0.0001)$, with each bait forming a distinct cluster on the NMDS for each system (ANOSIM; $\mathrm{R}=0.19 ; P=0.017$ for Brazilian savanna; ANOSIM; $\mathrm{R}=0.75 ; P=0.0010$ for riverbanks; and ANOSIM; $\mathrm{R}=0.54 ; P=0.0010$ for pastures with exotic grass; Fig. 3). Seven species (Trichillum externepunctatum Preudhomme de Borre, Uroxys sp., Dichotomius bos (Blanchard), Ontherus appendiculatus (Mannerheim), Onthophagus aff. hirculus, Canthidium aff. barbacenicum, and Canthon aff. tristis) contributed to $>80 \%$ of the observed differences in community structure (Table 2 ).

We captured representative species from all three foraging species in two baits. The pitfall baited with capybara dung collected 12 tunneler (46.15\%), 9 dweller $(34.62 \%)$, and 5 roller species $(19.23 \%)$, while pitfalls baited with human feces collected 16 tunneler (51.61\%), 8 dweller $(25.81 \%)$, and 7 roller species (22.58\%; Table 2).

\section{Discussion}

Our study reports for the first time that capybara dung attracts dung beetles in different Neotropical landscapes and may potentially be used by these animals. It is not surprising to find dung beetle species associated with the dung of these animals, because capybaras are native to the Neotropical region. In addition, the use of rodent dung by dung beetles is already reported (Anduaga and Halffter 1991, Lobo and Halffter 1994).

Traps baited with omnivorous human feces captured greater dung beetle richness and abundance in the three systems studied. In this study, $>90 \%$ of species were attracted to human feces. This bait is one of the most important baits for effective capturing dung beetles (e.g., Milhomenn et al. 2003), in both, forests (e.g., Filgueiras et al. 2009, Silva et al. 2012b) and in open areas such as pastures (e.g., Silva et al. 2012a). The greater attractiveness of baits from omnivores compared with herbivores was already known (e.g., Estrada et al. 1993, Whipple and Hoback 2012). This is probably because of the characteristics of the dung of carnivores, herbivores, and omnivores, as their nutritional contents differ, and this may affect their ability to attract the dung beetles (Hanski and Cambefort 1991, Whipple and Hoback 2012). For example, herbivore manure is composed mostly of cellulose and microbe fragments, while that of carnivores has a large amount of nitrogen (Hanski and Cambefort 1991). Manure of omnivorous animals presents a combination of the characteristics of carnivore and herbivore feces, appearing to be more attractive to dung beetles (Fincher et al. 1970, Martín-Piera and Lobo 1996, Filgueiras et al. 2009).

The dung beetle community attracted to human and capybara feces formed two distinct groups in the study sites, mainly because of the large number of species and individuals captured more frequently in traps baited with human feces than capybara dung. The composition of dung beetles attracted to the feces of carnivores, herbivores, and omnivores has been shown to vary (Whipple and Hoback 2012). Furthermore, the differential use of mammal dung by dung beetles, as found in our study, has also been reported to cattle and horse manure (Louzada and Carvalho e Silva 2009). 

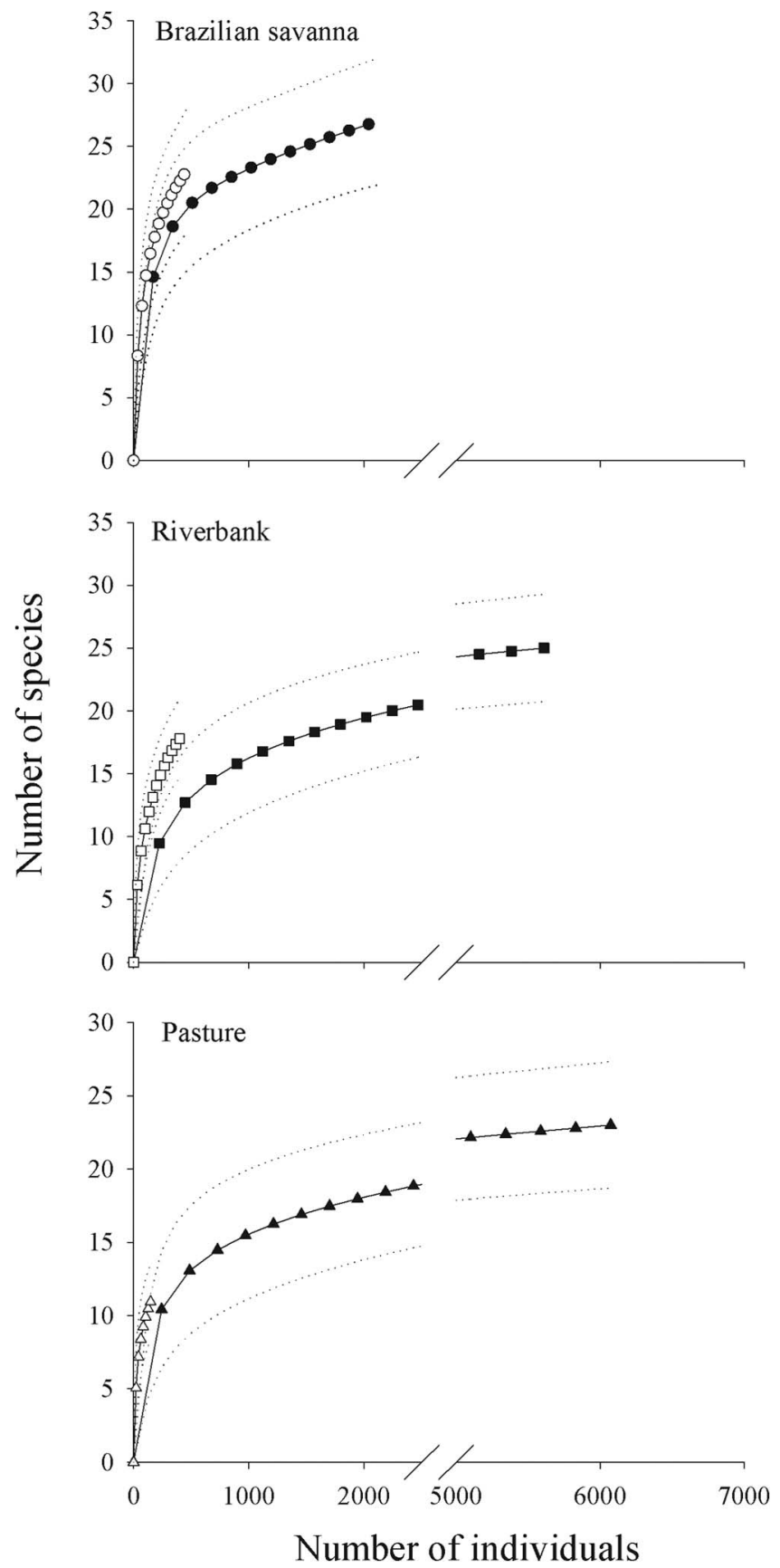

Fig. 1. Individual-based species accumulation curves for dung beetle communities (Coleoptera: Scarabaeinae) for different baits in the three systems. The dotted lines are $95 \% \mathrm{CI}$, illustrating that there was no significant difference between capybara dung and human feces. Black symbol represents human feces and white symbol represents capybara dung.

This indicates that the community structure of dung beetles can be different for relatively similar resources, such as these large herbivorous mammals, mainly because of the ability of dung beetles to distinguish different types of dung based on their volatile compounds (e.g., Dormont et al. 2010).

In this study, we believe that both feces types presented differences with regards to their physical prop- erties. The physical properties of capybara dung (low moisture content and elevated fiber content) would reduce the duration of the attractive period to dung beetles, which could explain our lower species capture rate of beetles on this bait type. However, the quality and attractiveness of the two types of feces is not only the result of the type of food consumed, as it may also be influence by internal physiology, digestion, and 


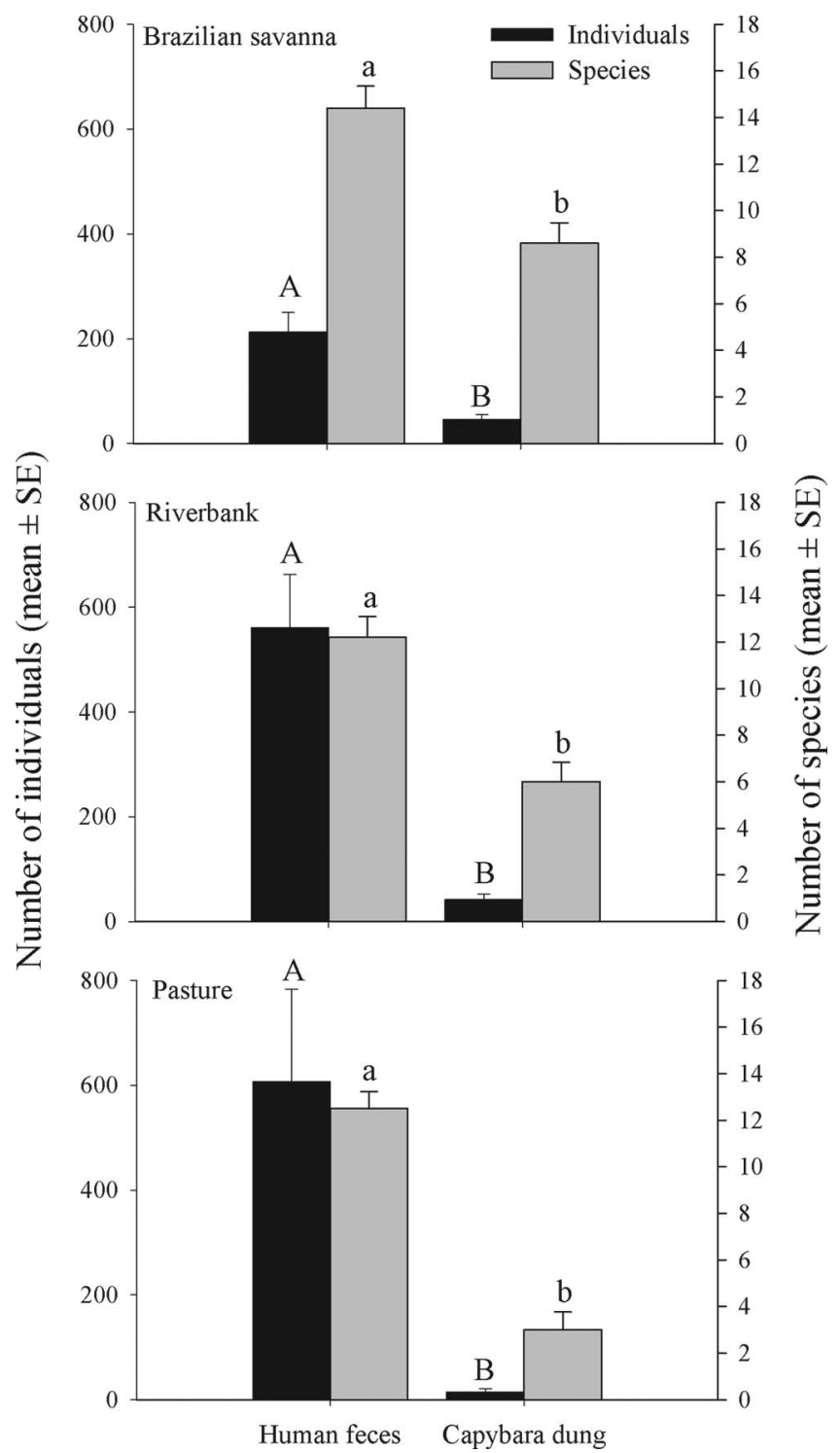

Fig. 2. Observed mean abundance and richness of dung beetles (Coleoptera: Scarabaeinae) sampled with human feces and capybara dung in the Brazilian savanna (Cerrado), riverbank, and pasture with exotic grass (Brachiaria spp.). Different letters for bars of the same color indicate a significant difference $(P<0.0001)$.

intestinal microflora of each mammal (Scholtz et al. 2009). The manure of mammals is one of the main resources used by dung beetles as food for larvae and adults, and as a substrate for oviposition. Thus, understanding the fauna of dung beetles attracted to different types of feces, especially native mammals, becomes important. Because most dung beetle species use a wide variety of mammalian feces (e.g., Louzada and Carvalho e Silva 2009, Correa et al. 2013), this type of information is useful for understanding the fauna of dung beetles in Neotropical region.

The functional guild organization of dung beetles is similar between capybara dung and human feces, with a predominance of tunnelers for both baits. This seems clear because of the 34 species sampled only three of them were exclusively found in capybara dung (see Table 2). However, these were singleton or doubleton species and, therefore can be occasional species. Because the capybaras defecate more often into the water, we believe this can be an explanation for the lack of a dung beetle specialist in this dung type.

In some regions of Brazil, capybaras have been bred in captivity. These animals could provide a much more environmentally sustainable source of protein than cattle ranching or bush meat hunting, especially given that they are widespread, common, and are prolific breeders requiring little in terms of area and food. However, in Brazil, this practice should be monitored 


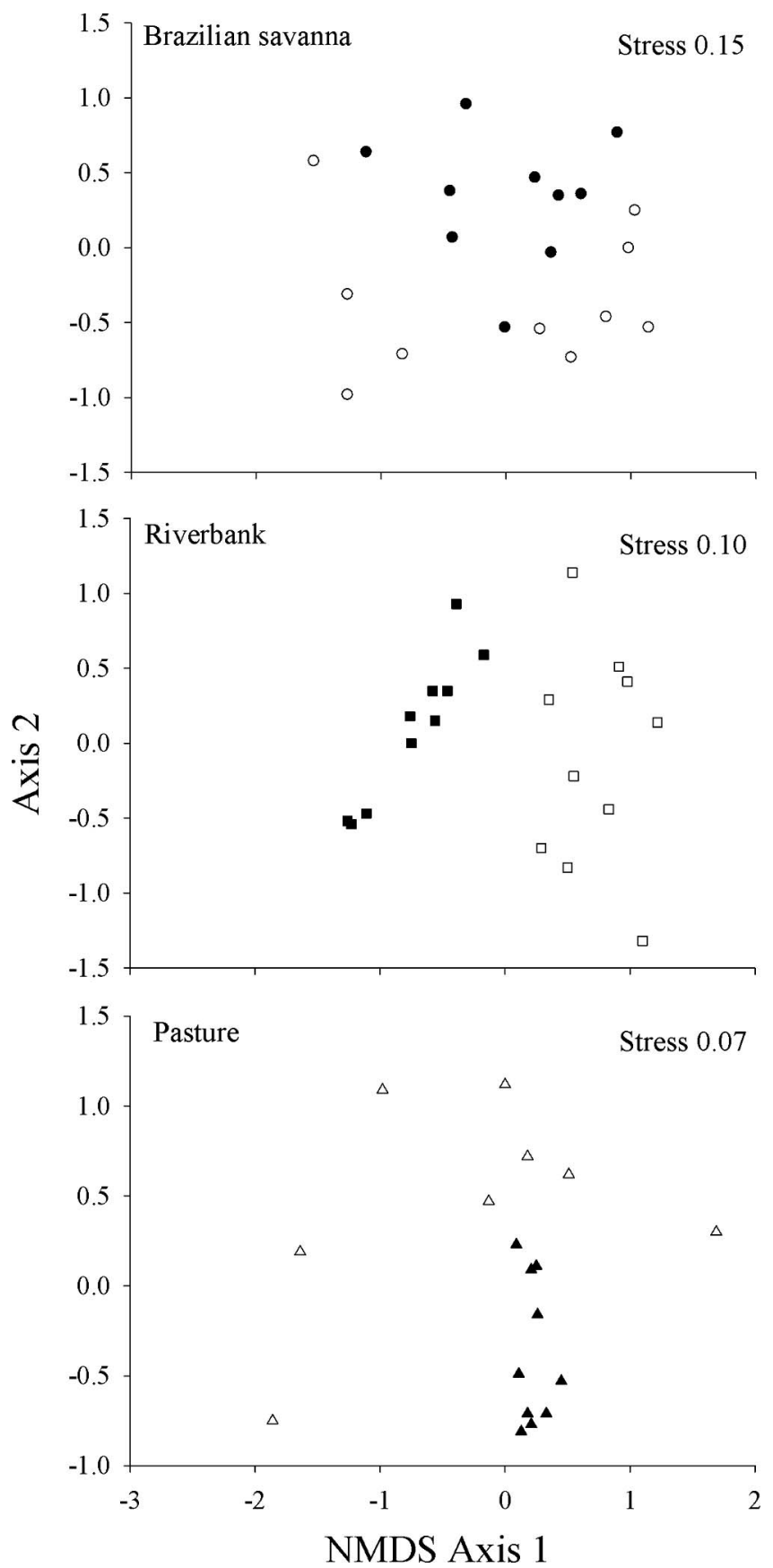

Fig. 3. Distribution pattern of the sampling points based on composition of the species according to grouping performed with NMDS using the Bray-Curtis index, based on the community structure of dung beetles (Coleoptera: Scarabaeinae) for each bait used in three systems. Black symbols represent human feces and white symbols represent capybara dung.

by environmental control agencies, as it is a protected species. Despite the smaller number of species and individuals captured in dung of capybara when compared with human feces, capybara dung is attractive to dung beetles. Because dung beetles are important species used amply in ecological research (e.g., Nichols et al. 2007; Braga et al. 2012, 2013; Larsen 2012), the knowledge of the communities associated with capybaras may be important in predicting the consequences of future management of their populations.

In summary, in this study we found that traps baited with human feces sampled greater abundance and richness of dung beetles than capybara dung in all environments studied. The community structure and 
Table 2. The average abundance of dung beetles (Coleoptera: Scarabaeinae) sampled with capybara dung and human feces in the Brazilian savanna (Cerrado), riverbank, and pasture with exotic grass (Brachiaria spp.)

\begin{tabular}{|c|c|c|c|c|c|}
\hline \multirow{2}{*}{ Taxon } & \multicolumn{2}{|c|}{ Mean abundance } & \multirow{2}{*}{$\begin{array}{c}\text { Contribution } \\
(\%)\end{array}$} & \multirow{2}{*}{$\begin{array}{c}\text { Cumulative } \\
(\%)\end{array}$} & \multirow{2}{*}{$\begin{array}{l}\text { Functional } \\
\text { guild }\end{array}$} \\
\hline & Capybara dung & $\overline{\text { Human feces }}$ & & & \\
\hline 1. Trichillum externepunctatum Preudhomme de Borre & 1.30 & 140 & 21.80 & 24.26 & Dweller \\
\hline 2. Uroxys sp. & 9.97 & 87.9 & 16.59 & 42.72 & Dweller \\
\hline 3. Dichotomius bos (Blanchard) & 3.87 & 48.6 & 9.19 & 52.95 & Tunneler \\
\hline 4. Ontherus appendiculatus (Mannerheim) & 2.50 & 50.4 & 8.03 & 61.88 & Tunneler \\
\hline 5. Onthophagus aff. hirculus & 6.20 & 26.8 & 6.23 & 68.82 & Tunneler \\
\hline 6. Canthidium aff. barbacenicum & 1 & 19.2 & 5.43 & 74.85 & Tunneler \\
\hline 7. Canthon aff. tristis & 2 & 12.2 & 5.00 & 80.43 & Roller \\
\hline 8. D. opacipennis Luederwaldt & 3.07 & 13.5 & 3.57 & 84.41 & Tunneler \\
\hline 9. D. nisus (Olivier) & 1.3 & 13.1 & 2.66 & 87.37 & Tunneler \\
\hline 10. C. aff. viride & 0.38 & 9.3 & 2.30 & 89.93 & Tunneler \\
\hline 11. Genieridium bidens (Balthasar) & 0.43 & 14.5 & 2.01 & 92.17 & Dweller \\
\hline 12. Deltochilum (Deltohyboma) sp. & 0.27 & 4.17 & 1.32 & 93.64 & Roller \\
\hline 13. Coprophanaeus sptizi (Pessôa) & 0 & 6.13 & 1.22 & 94.99 & Tunneler \\
\hline 14. Canthon histrio LePeletier and Serville & 0 & 1.5 & 0.83 & 95.92 & Roller \\
\hline 15. Ateuchus sp. 1 & 0.87 & 2.27 & 0.71 & 96.71 & Dweller \\
\hline 16. D. glaucus (Harold) & 0.03 & 3.23 & 0.68 & 97.47 & Tunneler \\
\hline 17. C. chalybaeus (Blanchard) & 0.07 & 1.73 & 0.65 & 98.19 & Roller \\
\hline 18. Eurysternus nigrovirens Génier & 0.13 & 1.87 & 0.43 & 98.67 & Dweller \\
\hline 19. E. caribaeus Herbst & 0 & 1.07 & 0.33 & 99.04 & Dweller \\
\hline 20. D. zikani (Luederwaldt) & 0.37 & 0.27 & 0.16 & 99.22 & Tunneler \\
\hline 21. Malagoniella puncticollis Blanchard & 0 & 1.17 & 0.15 & 99.38 & Roller \\
\hline 22. C. aff. breve & 0 & 0.37 & 0.13 & 99.52 & Tunneler \\
\hline 23. Phanaeus kirbyi Vigors & 0 & 0.23 & 0.08 & 99.61 & Tunneler \\
\hline 24. Diabroctis mimas L. & 0 & 0.17 & 0.07 & 99.68 & Tunneler \\
\hline 25. C. obscuriellus Schmidt & 0.07 & 0.1 & 0.06 & 99.75 & Roller \\
\hline 26. Digitonthophagus gazella (F.) & 0.10 & 0.13 & 0.05 & 99.8 & Tunneler \\
\hline 27. Canthon sp. & 0.03 & 0.1 & 0.04 & 99.84 & Roller \\
\hline 28. Ateuchus sp. 2 & 0.07 & 0.03 & 0.03 & 99.87 & Dweller \\
\hline 29. Ateuchus aff. carbonarius & 0.03 & 0.03 & 0.03 & 99.9 & Dweller \\
\hline 30. D. aff. cuprinus & 0.03 & 0.07 & 0.02 & 99.93 & Tunneler \\
\hline 31. Anomiopus pereirai (Martínez) & 0.07 & 0 & 0.02 & 99.95 & Dweller \\
\hline 32. Uroxys aff. corporaali & 0.07 & 0 & 0.02 & 99.98 & Dweller \\
\hline 33. D. sexdentatus (Luederwaldt) & 0.03 & 0 & 0.01 & 99.99 & Tunneler \\
\hline 34. C. ensifer (Germar) & 0 & 0.03 & 0.01 & 100.00 & Tunneler \\
\hline
\end{tabular}

The SIMPER analysis illustrates that the community structure of dung beetles on capybara dung was different from samples on human feces with respect to changes in average abundance of common species and the presence of exclusive species on both dung types.

species composition of dung beetles form distinct groups in the three systems studied, where seven species contribute to $>80 \%$ of this difference. In addition, we found that community of dung beetles on capybara dung is a subset of that found on human feces. Thus, changes in the amount of capybara dung will be important to biodiversity of dung beetles of the region if omnivore dung is relatively less abundant.

\section{Acknowledgments}

We thank Cristiano Lopes-Andrade (Federal University of Viçosa [UFV], Viçosa, Minas Gerais, Brazil) for providing space and equipment of the Laboratory of Systematics and Biology of Coleoptera for screening of Scarabaeinae, Fernando Z. Vaz-de-Mello (UFMT) for identification of the species of dung beetles, Cleilsom M. Cristaldo and Jorge A. de Deus Ricardo (UEMS) for the field support, Cassiano S. Rosa (UFV) and two anonymous reviewers for the fruitful comments on the manuscript. A.P. thanks Conselho Nacional de Desenvolvimento Científico e Tecnológico (CNPq, Brazil) for the scholarship granted (process number 140989/ 2011-0) and the Graduate Program in Entomology of the Federal University of Viçosa. C.M.A.C. thanks his father, Agenor M. Correa, for the encouragement and logistical support for execution of this research, CNPq for the scholarship granted (process number 134418/2013-1), and the
Graduate Program in Agronomy of the State University of Mato Grosso do Sul. V.K. thanks Coordenação de Aperfeiçoamento de Pessoal de Nível Superior (CAPES, Brazil) for the research grant received (PNPD institucional).

\section{References Cited}

Abot, A. R., A. Puker, T. L. Taira, S. R. Rodrigues, V. Korasaki, and H. N. Oliveira. 2012. Abundance and diversity of coprophagous beetles (Coleoptera: Scarabaeidae) caught with a light trap in a pasture area of the Brazilian Cerrado. Stud. Neotrop. Fauna Environ. 47: 53-60.

Almeida, S., J. Louzada, C. Sperber, and J. Barlow. 2011. Subtle-use change and tropical biodiversity: dung beetle communities in Cerrado grasslands and exotic pastures. Biotropica 43: 704-710.

Anduaga, S. 2007. Nuevos registros de escarabajos coprófagos (Coleoptera: Scarabaeidae) en detritus de madrigueras de Neotoma albigula Hartley (Rodentia: Muridae). Acta Zool. Mex. (N.S.) 23: 143-144.

Anduaga, S., and G. Halffter. 1991. Escarabajos asociados a madrigueras de roedores (Coleoptera: Scarabaeidae, Scarabaeinae). Folia Entomol. Mex. 81: 185-197.

Braga, R. F., V. Korasaki, L. D. Audino, and J. Louzada. 2012. Are dung beetles driving dung-fly abundance in traditional agricultural areas in the Amazon? Ecosystems 15: 1173-1181.

Braga, R. F., V. Korasaki, E. Andresen, and J. Louzada. 2013. Dung beetle community and functions along a habitat- 
disturbance gradient in the Amazon: a rapid assessment of ecological functions associated to biodiversity. PLoS ONE 8: e57786.

Clarke, K. R. 1993. Nonparametric analyses of changes in community structure. Aust. J. Ecol. 18: 117-143.

Clarke, K. R., and R. N. Gorley. 2006. Primer v. 6: computer program and user manual/tutorial. PRIMER-E Ltd., Plymouth, United Kingdom.

Clarke, K. R., and R. M. Warwick. 2001. Changes in marine communities: an approach to statistical analysis and interpretation, 2nd ed. PRIMER-E, Plymouth, United Kingdom.

Colwell, R. K. 2005. EstimateS: statistical estimation of species richness and shared species from samples, version 7.5. (http://viceroy.eeb.uconn.edu/ estimates).

Correa, C.M.A., A. Puker, V. Korasaki, and N. G. Oliveira. 2013. Dung beetles (Coleoptera, Scarabaeinae) attracted to sheep dung in exotic pastures. Rev. Bras. Entomol. 57: 113-116.

Crawley, M. J. 2002. Statistical computing: an introduction to data analysis using s-plus. Wiley, London, United Kingdom.

Dormont, L., P. Jay-Robert, J. M. Bessiere, S. Rapior, and J. P. Lumaret. 2010. Innate olfactory preferences in dung beetles. J. Exp. Biol. 213: 3177-3186.

Estrada, A., G. Halffter, R. Coates-Estrada, and D. A. Meritt Jr. 1993. Dung beetles attracted to mammalian herbivore (Alouatta palliata) and omnivore (Nasua narica) dung in the tropical rain forest of Los Tuxtlas, México. J. Trop. Ecol. 9: 45-54.

Filgueiras, B.K.C., C. N. Liberal, C.D.M. Aguiar, M.I.M. Hernández, and L. Iannuzzi. 2009. Attractivity of omnivore, carnivore and herbivore mammalian dung to Scarabaeinae (Coleoptera, Scarabaeidae) in a tropical Atlantic rainforest remnant. Rev. Bras. Entomol. 53: 422-427.

Fincher, G. T., T. B. Stewart, and R. Davis. 1970. Attraction of coprophagous beetles to feces of various animals. J. Parasitol. 56: 378-383.

Flechtmann, C.A.H., V. G. Tabet, and I. Quintero. 2009. Influence of carrion smell and rebaiting time on the efficiency of pitfall traps to dung beetle sampling. Entomol. Exp. Appl. 132: 211-217.

Halffter, G., and M. E. Favila. 1993. The Scarabaeinae (Insecta: Coleoptera) an animal group for analysing, inventorying and monitoring biodiversity in tropical rainforest and modified landscapes. Biol. Int. 27: 15-21.

Halffter, G., and E. G. Matthews. 1966. The natural history of dung beetles of the subfamily Scarabaeinae (Coleoptera: Scarabaeidae). Folia Entomol. Mex. 12-14: 1-312.

Hammer, O., D.A.T. Harper, and P. D. Ryan. 2001. Past: paleontological statistics software package for educations and taxa analysis. Paleontol. Electron. 4: 1-9.

Hanski, I., and Y. Cambefort. 1991. Dung beetle ecology. Princeton University Press, Princeton, NJ.

Hernández, M.I.M., and F. Z. Vaz-de-Mello. 2009. Seasonal and spatial species richness variation of dung beetle (Coleoptera, Scarabaeidae s. str.) in the Atlantic Forest of southeastern Brazil. Rev. Bras. Entomol. 53: 607-613.

Howden, H. F., and O. L. Cartwright. 1963. Scarab beetles of the genus Onthophagus Latreille North of Mexico. Proc. U.S. Natl. Mus. 114: 1-133.

Howden, H. F., and V. G. Nealis. 1975. Effects of clearing in a tropical rain forest on the composition of the coprophagous scarab beetle fauna (Coleoptera). Biotropica 7: 77-83.

Howden, H. F., O. L. Cartwright, and G. Halffter. 1956. Description de una especie mexicana de Onthophagus con anotaciones ecologicas sobre especies asociadas a nidos de animales y a cuevas. Acta Zool. Mex. (N.S.). 1: 1-16.

Korasaki, V., R. F. Braga, R. Zanetti, F.M.S. Moreira, F. Z. Vaz-de-Mello, and J. Louzada. 2013. Conservation value of alternative land-use systems for dung beetles in Amazon: valuing traditional farming practices. Biodivers. Conserv. 22: 1485-1499.

Larsen, T. H. 2012. Upslope range shifts of Andean dung beetles in response to deforestation: compounding and confounding effects of microclimatic change. Biotropica 44: $82-89$.

Larsen, T. H., and A. Forsyth. 2005. Trap spacing and transect design for dung beetle biodiversity studies. Biotropica 37: 322-325.

Lobo, J. M., and G. Halffter. 1994. Relaciones entre escarabajos (Coleoptera: Scarabaeidae) y nidos de tuza (Rodentia: Geomyidae): implicaciones biologicas y biogeograficas. Acta Zool. Mex. (N.S.) 62: 1-9.

Louzada, J.N.C., and P. R. Carvalho e Silva. 2009. Utilisation of introduced Brazilian pastures ecosystems by native dung beetles: diversity patterns and resource use. Insect Conserv. Divers. 2: 45-52.

Martín-Piera, F., and J. M. Lobo. 1996. A comparative discussion of trophic preferences in dung beetle communities. Misc. Zool. 19: 13-31.

Milhomenn, M. S., F. Z. Vaz-de-Mello, and I. R. Diniz. 2003. Técnicas para coletas de besouros copronecrófagos no Cerrado. Pesqui. Agropecu. Bras. 38: 1249-1256.

Nichols, E., T. Larsen, S. Spector, A. L. Davis, F. Escobar, M. Favila, and K. Vulinec. 2007. Global dung beetle response to tropical forest modification and fragmentation: a quantitative literature review and meta-analysis. Biol. Conserv. 137: 1-19.

R Development Core Team. 2013. R: a language and environment for statistical computing. R Foundation for Statistical Computing, Vienna, Austria. (http://www.R-project.org).

Scholtz, C. H., A.L.V. Davis, and U. Kryger. 2009. Evolutionary biology and conservation of dung beetles. Pensoft Publishers, Sofia, Bulgaria.

Silva, P. G., L. D. Audino, J. M. Nogueira, L. P. Moraes, and F. Z. Vaz-de-Mello. 2012a. Escarabeíneos (Coleoptera: Scarabaeidae: Scarabaeinae) de uma área de campo nativo no bioma Pampa, Rio Grande do Sul, Brasil. Biota Neotrop. 12: 246-253.

Silva, P. G., F. Z. Vaz-de-Mello, and R. A. Di Mare. 2012b. Attractiveness of different bait to the Scarabaeinae (Coleoptera: Scarabaeidae) in forest fragments in extreme Southern Brazil. Zool. Stud. 51: 429-441.

Vaz-de-Mello, F. Z. 2000. Estado atual de conhecimento dos Scarabaeidae s. str. (Coleoptera: Scarabaeoidea) do Brasil, pp. 183-195. In F. Martin Piera, J. J. Morrone, and A. Melic (eds.), Hacia un Proyecto CYTED Para el Inventario y Estimación de la Diversidad Entomológica en Ibe-Roamérica: PrIBES-2000. Sociedad Entomológica Aragonesa, Zaragoza, Spain.

Whipple, S. D., and W. W. Hoback. 2012. A comparison of dung beetle (Coleoptera: Scarabaeidae) attraction to native and exotic mammal dung. Environ. Entomol. 41: 238-244.

Woods, C. A., and C. W. Kilpatrick. 2005. Infraorder hystricognathi, pp. 1538-1600. In D. E. Wilson and D. M. Reeder (eds.), Mammal Species of the World: A Taxonomic and Geographic Reference. John Hopkins University Press, Baltimore, MD.

Received 11 April 2013; accepted 16 August 2013. 